\title{
REVIEW
}

\section{Cardiac index during therapeutic hypothermia: which target value is optimal?}

\author{
Raphaël Giraud, Nils Siegenthaler, Karim Bendjelid* \\ This article is one of ten reviews selected from the Annual Update in Intensive Care and Emergency Medicine 2013 and co-published as a series \\ in Critical Care. Other articles in the series can be found online at http://ccforum.com/series/annualupdate2013. Further information about the \\ Annual Update in Intensive Care and Emergency Medicine is available from http://www.springer.com/series/8901.
}

\begin{abstract}
Introduction
Mild therapeutic hypothermia is now recognized as standard therapy in patients resuscitated from out-ofhospital cardiac arrest (OHCA), and is recommended in comatose patients suffering from cardiac arrest related to ventricular fibrillation (VF) [1]. In these patients, maintaining an adequate tissue oxygen delivery $\left(\mathrm{DO}_{2}\right)$ is crucial. However, during hypothermia, clinical signs of hypoperfusion such as cold, clammy skin and delayed capillary refill are not reliable and monitoring devices must, therefore, be used to measure or estimate the cardiac index (CI). However, there are no recommendations regarding the target value of $\mathrm{CI}$ in the hypothermic patient. In this article, the authors attempt to provide clinicians with some rationale to guide their therapy for the management of $\mathrm{CI}$ in patients treated with mild therapeutic hypothermia.
\end{abstract}

\section{Mild therapeutic hypothermia}

Neurologic outcome and survival rates are improved in patients treated with mild therapeutic hypothermia $[2,3]$. The reason for the improved survival is probably related to the preservation of cerebral function. During mild therapeutic hypothermia, clinical data demonstrate that heart rate is significantly reduced, an effect that usually improves left ventricular (LV) filling [4]. Whereas CI usually decreases with hypothermia, mild therapeutic hypothermia exerts positive inotropic effects in isolated human and pig myocardium. The phenomenon of increased inotropism during mild therapeutic hypothermia is not associated with increased sarcoplasmic reticulum $\mathrm{Ca}^{2+}-$ content or increased $\mathrm{Ca}^{2+}$-transients [5]. Moreover, recent studies using animal species and in humans have provided accumulating evidence suggesting that mild therapeutic

*Correspondence: karim.bendjelid@hcuge.ch

Intensive Care Service, Geneva University Hospitals, 4 Rue Gabrielle Perret-Gentil, $\mathrm{CH}-1211$ Geneva 14, Switzerland hypothermia may also improve cardiac performance $[5,6]$. Therefore, the higher survival rates may also be related to positive hemodynamic effects of cooling in patients already suffering from cardiac disease. Furthermore, a study about the hemodynamic effects of mild therapeutic hypothermia in 20 consecutive patients admitted in cardiogenic shock after successful resuscitation from OHCA showed that these patients seemed to benefit from mild therapeutic hypothermia in terms of myocardial performance, catecholamine usage, and survival when compared to a historic control group of matched patients treated without hypothermia [7]. Moreover, animal studies have shown that, in myocardial infarction, hypothermia decreases oxygen consumption and infarct size [8]. The positive inotropic effect of mild therapeutic hypothermia measured by systolic function has also been demonstrated in in vivo studies [5,9] and can be measured echocardiographically by the significant increase in ejection fraction $(E F)$ and the augmented contraction velocity measured by pulse contour analysis. However, as shown by Lewis et al., increasing the heartrate (HR) under hypothermic conditions has a negative impact on LV contractility [9]. Although systolic performance is clearly improved at all temperature steps investigated, pronounced hypothermia may impair diastolic function [10]. However, in the temperature range recommended for mild therapeutic hypothermia in cardiac arrest patients (32$\left.34{ }^{\circ} \mathrm{C}\right)[11,12]$, diastolic function seems to be preserved [6]. Although mild therapeutic hypothermia may have direct repercussions on the myocardium, a study by Bernard et al. showed no clinically significant effect on cardiac arrhythmias in the hypothermia group [13].

\section{Which $\mathrm{Cl}$ target value is optimal in hypothermic patients}

In order to maintain perfusion pressure and as a result of hypothermia, the systemic vascular resistance (SVR) increases. As a result, mean arterial pressure (MAP) 
decreases only slightly with mild therapeutic hypothermia despite a significant decrease in CI. This reaction to hypothermia is explained by the vasoconstriction of peripheral arteries and arterioles [14] and the stabilization of MAP reducing the vasopressor dosage. Furthermore, the need for volume in mild therapeutic hypothermia can be explained by the induction of 'cold diuresis' through a combination of increased venous return (vasoconstriction), activation of atrial natriuretic peptide, decreased levels of antidiuretic hormone and renal antidiuretic hormone receptor levels, and tubular dysfunction $[15,16]$.

There is considerable confusion about the standard of care for critically ill patients undergoing mild therapeutic hypothermia, in particular related to the subject of hemodynamic optimization. For example, for many years it was commonly taught that although the patient's body temperature decreases, CI values should be as normal as those of normothermic patients. However, although a significant decrease in CI may lead to inadequate organ perfusion in normothermic patients, Bergman et al. failed to demonstrate that a low cardiac output caused lower mixed venous oxygen saturation $\left(\mathrm{SvO}_{2}\right)$ in patients undergoing mild therapeutic hypothermia [17]. This suggests that, parallel to the drop in CI, oxygen consumption decreases also because of the lower body temperature. In other words, during mild therapeutic hypothermia, the workload for the heart may be lower because of the lower resting energy metabolism required at a lower body temperature [17]. In fact, the overall metabolic rate decreases by approximately $8 \%$ per ${ }^{\circ} \mathrm{C}$ amounting to a decrease of $32 \%$ when the target temperature of $33{ }^{\circ} \mathrm{C}$ is reached, thus oxygen consumption and $\mathrm{CO}_{2}$ production are reduced. This effect holds true for the heart itself, in which the diminished heart rate reduces the metabolic demand even further. In addition, mild therapeutic hypothermia induces coronary vasodilatation and increases myocardial perfusion [18]. This belief is corroborated by the fact that under cardiopulmonary bypass $(\mathrm{CPB})$, a technique performed with moderate systemic hypothermia $\left(28\right.$ to $\left.32{ }^{\circ} \mathrm{C}\right)$, blood flow and CI are maintained between 2.2 and $2.41 / \mathrm{min} / \mathrm{m}^{2}$, without detrimental effects.

\section{Bohr effects during alpha- and Ph-stat hypothermia}

During hypothermia, $\mathrm{SvO}_{2}$ measurement depends on the blood gas analysis technique (alpha-stat, pH-stat) used and the impact of the decrease in temperature on the affinity of hemoglobin for oxygen (Bohr Effect). Indeed, whether a pH-stat or alpha-stat strategy is the ideal acidbase management during severe hypothermic circulatory arrest has been the subject of contention. Advocates of $\mathrm{pH}$-stat management (which aims for a partial pressure of $\mathrm{CO}_{2}\left[\mathrm{PCO}_{2}\right]$ of $40 \mathrm{~mm} \mathrm{Hg}$ and $\mathrm{pH}$ of 7.40 at the patient's actual temperature) claim that the resulting higher $\mathrm{CO}_{2}$ causes cerebral vasodilatation and faster and more homogeneous cooling. They also suggest that the resulting acidotic protocol of this acid-base management facilitates the release of oxygen from hemoglobin, a fact that offsets the hypothermic leftward shift of the oxygen dissociation curve (Bohr Effect). On the other hand, proponents of alpha-stat management, in which there is an alkaline drift during hypothermia, state that this allows cerebral auto-regulation to continue and that cellular transmembrane $\mathrm{pH}$ gradients and protein function are maintained. Indeed, when alpha-stat $\mathrm{pH}$ management is used, the $\mathrm{PCO}_{2}$ decreases (and solubility increases); thus a hypothermic patient with a $\mathrm{pH}$ of 7.40 and an arterial $\mathrm{PCO}_{2}$ of $40 \mathrm{~mm} \mathrm{Hg}$ (measured at $37^{\circ} \mathrm{C}$ ) will, in reality, have a lower $\mathrm{PaCO}_{2}$ and this will manifest as a relative respiratory alkalosis coupled with decreased cerebral blood flow. In addition, the alkaline $\mathrm{pH}$ improves cerebral protection during the ischemic insult. However, there is evidence to suggest that the best technique for acid-base management in patients undergoing deep hypothermic circulatory arrest during cardiac surgery is also dependent upon the age of the patient with better results using alpha-stat in the adult than in the pediatric patient [19].

\section{What exactly does $\mathrm{SvO}_{2}$ mean during mild therapeutic hypothermia?}

Although mild therapeutic hypothermia induces a decrease in both $\mathrm{HR}$ and $\mathrm{CI}$, in the majority of cases $\mathrm{SvO}_{2}$ value remains stable (Fig. 1). However, during this condition there is sometimes an increase in systemic arterial lactate levels and it is unclear whether this is caused by increased anaerobic metabolism. The pathogenesis of this disorder is uncertain, but it appears not to relate to inadequate $\mathrm{DO}_{2}$ [20]. Therefore, the use of inotropic drugs in order to increase CI to 'normal' values may be futile or even harmful because of its negative impact on LV contractility, ventricular arrhythmias and increase in oxygen uptake $\left(\mathrm{VO}_{2}\right)$. The best indicator of good tissue perfusion in patients undergoing mild therapeutic hypothermia seems to be $\mathrm{SvO}_{2}$ and not CI. However, another misconception arises from the relatively large differences between $\mathrm{SvO}_{2}$ values measured in patients undergoing the alpha-stat and the $\mathrm{pH}$-stat acidbase management. Indeed, oxygen extraction is decreased during mild therapeutic hypothermia as the oxyhemoglobin dissociation curve shifts left (Bohr Effect). And, the increased oxygen affinity of hemoglobin during this hypothermic state could also be aggravated by the alkalotic environment (oxyhemoglobin dissociation curve shifts left; Bohr Effect) produced by the alpha-stat method, to the point of developing tissue hypoxia [21]. In 

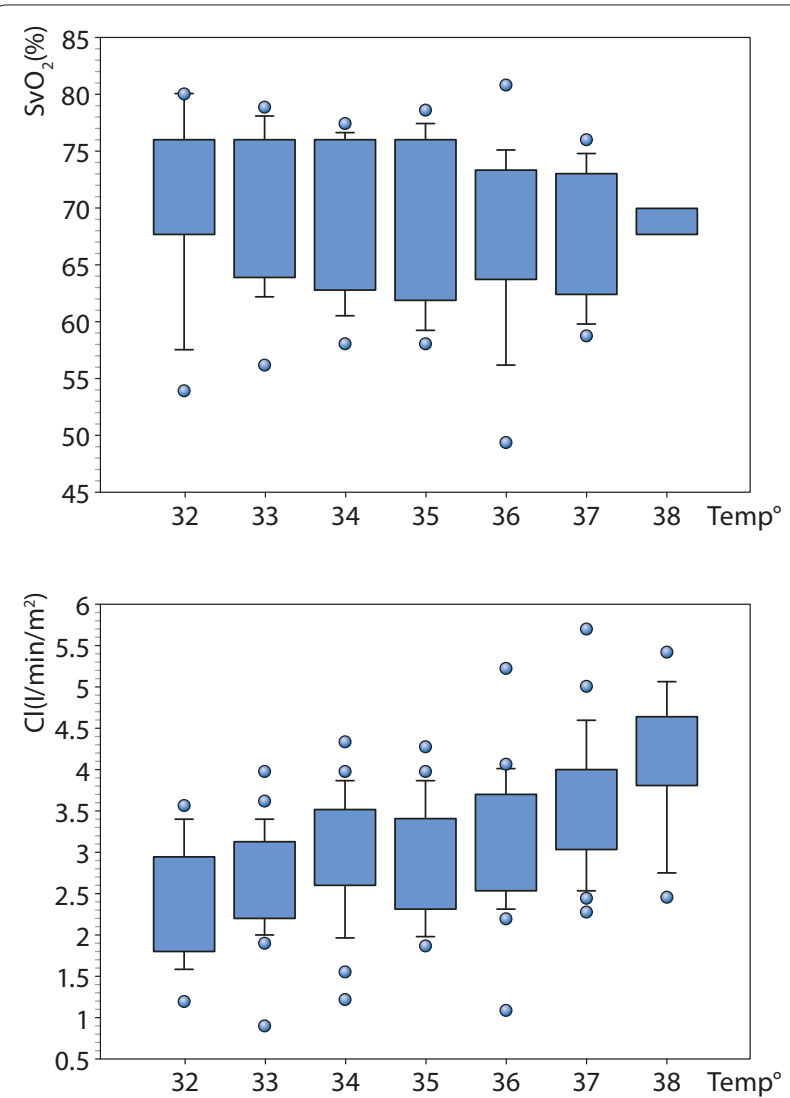

Figure 1. Effects of temperature level on cardiac index (Cl) and mixed venous oxygen saturation $\left(\mathrm{SvO}_{2}\right)$ values in 27 patients undergoing mild therapeutic hypothermia (alpha-Stat management. Bendjelid et al., unpublished data). Please note that a continuous decrease in $\mathrm{Cl}$ is not associated with the same decrease in $\mathrm{SvO}_{2}$ values.

this sense, $\mathrm{SvO}_{2}$ monitoring could be a valuable tool to optimize $\mathrm{DO}_{2}$ in the hypothermic patient, where the optimal value of $\mathrm{SvO}_{2}$ is adjusted according to the acidbase management of blood gas measurements.

\section{Conclusion}

Although mild therapeutic hypothermia is now recognized as the standard therapy in patients resuscitated from OHCA, optimal target CI values are not clear. However, based on the pathophysiology of the effects of hypothermia, it is possible to find answers regarding the hemodynamic management of these patients. Indeed, it seems futile and even dangerous to try to normalize CI to 'normal' values. However, it does seem appropriate to monitor $\mathrm{SvO}_{2}$ values and arterial lactate levels in these patients, taking into account the impact of hypothermia and acid-base management on the oxyhemoglobin dissociation curve.

Competing interests

The authors declare that they have no competing interests.

\section{List of abbreviations used}

Cl: cardiac index; CPB: culmonary bypass; $\mathrm{DO}_{2}$ : oxygen delivery; EF: ejection fraction; HR: heart rate; LV: left ventricular; MAP: mean arterial pressure; $O H C A$ : out-of-hospital cardiac arrest; $\mathrm{PCO}_{2}$ : partial pressure of $\mathrm{CO}_{2}$; SCR: systemic vascular resistance; $\mathrm{S}_{\mathrm{V}} \mathrm{O}_{2}$ : venous oxygen saturation; $\mathrm{VO}_{2}$ : oxygen uptake.

Published: 19 March 2013

\section{References}

1. Arrich J, Holzer M, Herkner H, Mullner M: Hypothermia for neuroprotection in adults after cardiopulmonary resuscitation. Cochrane Database Syst Rev 2009, CD004128

2. The Hypothermia after Cardiac Arrest Study Group: Mild therapeutic hypothermia to improve the neurologic outcome after cardiac arrest NEngl J Med 2002, 346:549-556.

3. Holzer M, Bernard SA, Hachimi-Idrissi S, Roine RO, Sterz F, Mullner M: Hypothermia for neuroprotection after cardiac arrest: systematic review and individual patient data meta-analysis. Crit Care Med 2005, 33:414-418.

4. Reil JC, Bohm M: The role of heart rate in the development of cardiovascular disease. Clin Res Cardiol 2007, 96:585-592.

5. Weisser J, Martin J, Bisping E, Maier LS, Beyersdorf F, Hasenfuss G, Pieske B: Influence of mild hypothermia on myocardial contractility and circulatory function. Basic Res Cardiol 2001, 96:198-205.

6. Jacobshagen C, Pelster T, Pax A, Horn W, Schmidt-Schweda S, Unsöld BW, Seidler T, Wagner S, Hasenfuss G, Maier LS: Effects of mild hypothermia on hemodynamics in cardiac arrest survivors and isolated failing human myocardium. Clin Res Cardiol 2010, 99:267-276.

7. Zobel C, Adler C, Kranz A, Seck C, Pfister R, Hellmich M, Kochanek M, Reuter H: Mild therapeutic hypothermia in cardiogenic shock syndrome. Crit Care Med 2012, 40:1715-1723.

8. Miki T, Liu GS, Cohen MV, Downey JM: Mild hypothermia reduces infarct size in the beating rabbit heart: a practical intervention for acute myocardial infarction? Basic Res Cardiol 1998, 93:372-383.

9. Lewis ME, Al-Khalidi AH, Townend JN, Coote J, Bonser RS: The effects of hypothermia on human left ventricular contractile function during cardiac surgery. J Am Coll Cardiol 2002, 39:102-108

10. Fischer UM, Cox Jr. CS, Laine GA, Mehlhorn U, Allen SJ: Mild hypothermia impairs left ventricular diastolic but not systolic function. J Invest Surg 2005, 18:291-296

11. Neumar RW, Nolan JP, Adrie C, Akibi M, Berg RA, Böttinger BW, Callaway C, Clark RS, Geocardin RG, Jauch EC, Kern KB, Laurent I, Longstreth WT Jr, Merchant RM, Morley P, Morrison LJ, Nadkarni V, Peberdy MA, Rivers EP, Rodriguez-Nunez A, Sellke FW, Spaulding C, Sunde K, Vanden Hoek T: Postcardiac arrest syndrome: epidemiology, pathophysiology, treatment, and prognostication. A consensus statement from the International Liaison Committee on Resuscitation (American Heart Association, Australian and New Zealand Council on Resuscitation, European Resuscitation Council, Heart and Stroke Foundation of Canada, InterAmerican Heart Foundation, Resuscitation Council of Asia, and the Resuscitation Council of Southern Africa); the American Heart Association Emergency Cardiovascular Care Committee; the Council on Cardiovascular Surgery and Anesthesia; the Council on Cardiopulmonary, Perioperative, and Critical Care; the Council on Clinical Cardiology; and the Stroke Council. Circulation 2008, 118:2452-2483.

12. Nolan JP, Neumar RW, Adrie C, Akibi M, Berg RA, Böttinger BW, Callaway C, Clark RS, Geocardin RG, Jauch EC, Kern KBm, Laurent I, Longstreth WT, Merchant RM, Morley P, Morrison LJ, Nadkarni V, Peberdy MA, Rivers EP, Rodriguez-Nunez A, Sellke FW, Spaulding C, Sunde K, Hoek TV: Post-cardiac arrest syndrome: epidemiology, pathophysiology, treatment, and prognostication. A Scientific Statement from the International Liaison Committee on Resuscitation; the American Heart Association Emergency Cardiovascular Care Committee; the Council on Cardiovascular Surgery and Anesthesia; the Council on Cardiopulmonary, Perioperative, and Critical Care; the Council on Clinical Cardiology; the Council on Stroke. Resuscitation 2008, 79:350-379.

13. Bernard SA, Gray TW, Buist MD, Jones BM, Silvester W, Gutteridge G, Smith K Treatment of comatose survivors of out-of-hospital cardiac arrest with induced hypothermia. N Eng/ J Med 2002, 346:557-563.

14. Reuler JB: Hypothermia: pathophysiology, clinical settings, and management. Ann Intern Med 1978, 89:519-527.

15. Allen DE, Gellai M: Mechanisms for the diuresis of acute cold exposure: role 
for vasopressin? Am J Physiol 1993, 264:R524-R532.

16. Polderman $\mathrm{KH}$, Tjong Tjin Joe R, Peerdeman SM, Vandertop WP, Girbes AR: Effects of therapeutic hypothermia on intracranial pressure and outcome in patients with severe head injury. Intensive Care Med 2002, 28:1563-1573.

17. Bergman R, Braber A, Adriaanse MA, van Vugt $R$, Tjan DH, van Zanten AR: Haemodynamic consequences of mild therapeutic hypothermia after cardiac arrest. Eur J Anaesthesiol 2010, 27:383-387.

18. Frank SM, Satitpunwaycha P, Bruce SR, Herscovitch P, Goldstein DS: Increased myocardial perfusion and sympathoadrenal activation during mild core hypothermia in awake humans. Clin Sci (Lond) 2003, 104:503-508.

19. Abdul Aziz KA, Meduoye A: Is pH-stat or alpha-stat the best technique to follow in patients undergoing deep hypothermic circulatory arrest? Interact Cardiovasc Thorac Surg 2010, 10:271-282.
20. Raper RF, Cameron G, Walker D, Bowey CJ: Type B lactic acidosis following cardiopulmonary bypass. Crit Care Med 1997, 25:46-51.

21. Miyamoto TA, Miyamoto KJ: Is it justified to disregard the Bohr effect during alpha-stat hypothermia? Ann Thorac Surg 2000, 69:973-975.

doi:10.1186/cc12523

Cite this article as: Giraud R, et al.: Cardiac index during therapeutic hypothermia: which target value is optimal? Critical Care 2013, 17:214 